\title{
Is public-private partnership a panacea for infrastructure development? The case of Beijing National Stadium
}

\author{
Yongjian Ke
}

\begin{abstract}
Public-private partnership (PPP) is such a hot concept that nowadays it is discussed everywhere be it a public sector management journal or a public sector management conference. Governments subject to severe fiscal pressure in developing countries like China, where PPP law is not in place yet, regard it as a panacea or fixed solution for infrastructure development. This paper hence attempts to provide reference to this point by investigating the Beijing National Stadium. There was a significant change in the Project Company on 20 August 2009. Three main reasons for the contract change were (1) wrong identification of the retractable roof as one of the output specifications, (2) adoption of PPP without a careful feasibility study and (3) strong government interference like suspension of selling name-right and prohibition of holding small-scale or small events. It was found that PPP would not be more appropriate than conventional procurement in this project. It was therefore proved that PPP is not a panacea for infrastructure development. It is expected that a review of the Beijing National Stadium can provide valuable information for when and how to implement PPPs. More considerations on receiving value for money in the whole project lifecycle (including the operation) should be taken in a PPP project.
\end{abstract}

Keywords: public-private partnership; Beijing National Stadium; social infrastructure; China

\section{Introduction}

Public-private partnership (PPP) is a joint working arrangement between the public and private sectors to deliver policies, services and infrastructure (HM Treasury 2011). In a typical PPP arrangement, a group of private investors finance and manage the construction of projects, maintain and operate facilities for a long period and at the end of the concession period transfer facilities to the government (Tieva \& Junnonen 2009). The use of PPP to involve private sector investment in the public provision of infrastructure has become common in recent years (Chan et al. 2010a). Projects that require large upfront investments, such as highways, urban rails, bridges, water and sewage treatment plants, are now usually provided via PPP modality (Engel et al. 2010).

With the continuous economic growth in China, the demand for infrastructures is increasing. To meet the growing development needs, the Chinese government has been proactive in promoting private involvement and investment in the infrastructure development. At the executive meeting of the State Council on 31 July 2013, Premier Keqiang Li stated that the government will continuously

Copyright: International Journal of Construction Management (C) 2014 Yongjian Ke. This is an Open Access article distributed under the terms of the Creative Commons Attribution 4.0 Unported (CC BY 4.0) License (https://creativecommons.org/licenses/by/4.0/), allowing third parties to copy and redistribute the material in any medium or format and to remix, transform, and build upon the material for any purpose, even commercially, provided the original work is properly cited and states its license.

Citation: Ke, Y. (2014). Is public-private partnership a panacea for infrastructure development? the case of Beijing National Stadium. International Journal of Construction Management, 14(2), 90100. doi: $\underline{10.1080 / 15623599.2014 .899127}$

Corresponding author: Yongjian Ke; Email - Yongjian.Ke@uts.edu.au 
support private investment and various investment entities will be treated equally. The central government also claimed to further widen market access of public services to eligible private investors with sound credit (Xinhuanet 2013). It is expected that private investors would get more involved in infrastructure development via PPP mode.

However, it is worth highlighting that PPP is not a panacea or a quick fix solution to deliver project financing and realization (UNIDO 1996; European Commission 2003; Chen 2009). It has been criticized for the high-risk exposure, lengthy delays in negotiation and project accountability concerns (Chan et al. 2010a). As an emerging PPP country, the regulatory and institutional frameworks for PPP in China are still not mature and are evolving (Chan et al. 2010a). There is currently no guidance for value for money assessment mechanism to ensure that PPP is the most appropriate option. Because of the great pressure on the government's budget for infrastructure development, the need for infrastructure to be developed may usually override concerns around the efficiency of its development and operation. The decision to adopt PPP would then be made despite the specific conditions of the target project. The government officials make decision based on their own judgments or preferences, while the public society, including professionals or academicians, has little influence on the decision-making (Sachs et al. 2007; Ke et al. 2012). In response to this issue, this paper aims to investigate when a PPP is the best option and how PPP should be done.

\section{Literature Review}

PPP has been popularly used in infrastructure development worldwide. Infrastructures are of two types: economic infrastructures (e.g., roads, tunnels, bridges) and social infrastructures (e.g., hospitals, schools, prisons). Economic infrastructures denote a subset of infrastructures that are characterized by demand-based revenue streams, while social infrastructures are those that typically include assets accommodating social services.

PPP is less difficult to apply in economic infrastructures that are financially more attractive to private investors (Jefferies \& McGeorge 2009). There is extensive literature investigating all kinds of issues in different sectors. For example, Lee and Yu (2011) studied the service delivery on household connections in Taiwan's sewer PPP projects, Sharma and Nayak (2013) developed an isodynamic model in PPP water management, Meduri and Annamalai (2013) compared the unit costs of public and PPP road projects in India and Ashuri et al. (2012) proposed a risk-neutral pricing approach for evaluating PPP highway projects.

The PPP model was first used for social public projects like schools, hospitals and prisons in the United Kingdom, Australia and United States. Over the years, these projects have further expanded to include sports arenas, art and exhibition facilities, colleges for higher education, etc. (Hodge \& Greve 2005). Some specific examples of social PPP projects are the Victoria Dock Primary School, which was the first private finance initiative (a form of PPP) school built in the United Kingdom (Gibson \& Davies 2008), and the Asia World Expo in Hong Kong. The success of these projects widened the scope of using PPP (Chan et al. 2010b). The continuous use of the PPP model for social projects has demonstrated that this arrangement could also be very successful in achieving the targeted outcomes (Malone 2005).

Given that the driving force for private investors in a PPP is to obtain a reasonable investment return, it is understandable that the government needs to make social PPPs more attractive to the private investors. Otherwise, the private investors may be deterred by the high transaction costs and low operation revenue of social PPPs (Curnow et al. 2005). This is in direct contrast to the available opportunities in economic PPP projects (Jefferies \& McGeorge 2009). 
There are many other problems/disadvantages as well with PPP projects: (1) The impact of risks (arising from multiple sources including the political, social, technical, economic and environmental factors) to project objectives in completing a PPP project is usually significant (Koppenjan 2005). (2) PPP projects often require extensive expertise input and take long time in deal negotiation (Li et al. 2005). (3) PPP in public projects typically face political and social issues such as land resumption, employment, heritage and environmental protection, which could result in public opposition, overblown costs and delays in the projects ( $\mathrm{Li}$ et al. 2005). (4) Success in finding financially strong partners in a PPP project is considered difficult, especially where there is a lack of mature financial engineering techniques (Grimsey \& Lewis 2004).

\section{Gap in knowledge}

In countries like the United Kingdom, Australia and Hong Kong, there are detailed PPP guides, which clearly indicate the procedure and method to evaluate the value for money for PPP and traditional delivery. In Hong Kong for example, in the early stages, when it might not be clear whether a PPP or another delivery option will be the best option to resolve the issues, a business case will often be handled in two stages: stage 1 and stage 2 . Stage 1 business case study involves a high level selection from different delivery options, and stage 2 business case study includes a detailed analysis of the costs, benefits and risks of the PPP option to the government, critical success factors, procurement strategy, risk management strategy, etc. (Efficiency Unit 2008).

In China, however, laws and regulations especially for those related to PPP are still not mature and are evolving (Chen 2009). There is currently no guidance for value for money assessment or other mechanisms to ensure that a PPP is the optimal financial option (Chan et al. 2010a). The government officials usually make decisions based on their own judgments or preferences, while the public society, including professionals or academicians, has little or negligible influence on the decision (Sachs et al. 2007; Ke et al., 2012). Under such circumstances, many local governments consider PPP as a quick fix solution to deliver infrastructures. The problem is that the adoption of PPP in an infrastructure project, especially a social infrastructure project with less financial attractiveness, may lead to a failure when it is not the best procurement option. This paper hence attempts to investigate the appropriateness of PPP adoption in the infrastructure development in China by a case study.

\section{Research method}

Case study can be an effective research approach for learning lessons from front-line projects and providing management implications to future infrastructure investors (Yin 2002). Therefore, a case study would be adopted in this paper to prove the viewpoint that PPP is not a quick fix solution to deliver infrastructures as well as to obtain lessons of when and how to adopt PPP in the infrastructure development in China.

The Beijing National Stadium is not only one of the most remarkable sport facilities in the world, but also the first PPP sport facility in China and it is therefore worth investigating this project. Another reason for choosing the Beijing National Stadium as a case study for this paper is that there was a significant change in the Project Company on 20 August 2009. The Beijing Municipal Government now has a $58 \%$ stake in the company and directly takes the lead of operation management. Instead of having a 30-year of exclusive concession period, the China International Trust and Investment Corporation (CITIC) Consortium became a permanent stakeholder with a $42 \%$ shareholding (National Stadium 2009). In light of the transfer of main stakeholder in this project from private 
consortium to government, it is hence expected that a review of the Beijing National Stadium can provide valuable information for when and how to implement PPPs.

\section{The case of Beijing National Stadium}

\subsection{Background}

Nowadays Olympics Games is no longer a sports event but also an urban regeneration effort. Many international cities showed great enthusiasm in bidding for hosting the Olympics, hoping to solve urban problems and boost growth in a short term (Hiller 2000). However, there were much higher stakes in Beijing's bid and preparations for the Olympics. It became a national event and a symbolic showcase through which the central government of China intended to demonstrate to the world the country's economic achievements (Ren 2008). It was in this context that the need to build a national stadium appeared.

Public interest in the Beijing National Stadium fell at two levels (Liu et al. 2010): project level and state level. At the project level, the design, financing, construction, operation and maintenance of the project could be carried out in accordance with the demands of hosting the games. On the other hand, at the state level, the project was expected to emphasize Chinese creativity in the organization and management of the games. It was hoped that the stadium would become a landmark and milestone project, which would help in both accelerating the modernization of Beijing and promoting national economic development. It could be seen that the Beijing National Stadium project was not only a municipal project in Beijing but also an important event in the whole country that attracted great attention of the central government and the public.

\subsection{Project development process}

The operation and maintenance of a sport facility is always a critical issue. The fact that many sports facilities for the 2008 Beijing Olympic Games were developed via PPP reflected the Chinese government's belief that such facilities could be built and operated more efficiently that way (Liu et al. 2010). However, unlike a normal PPP project, Beijing Municipal Government (BMG) entrusted the Beijing Municipal Development Planning Commission (BMDPC, currently known as Beijing Municipal Commission of Development and Reform, BMCDR) to conduct the biddings for the design and concession of the stadium at the same time in October 2002. The detailed milestones of the development process are shown in Figure 1.

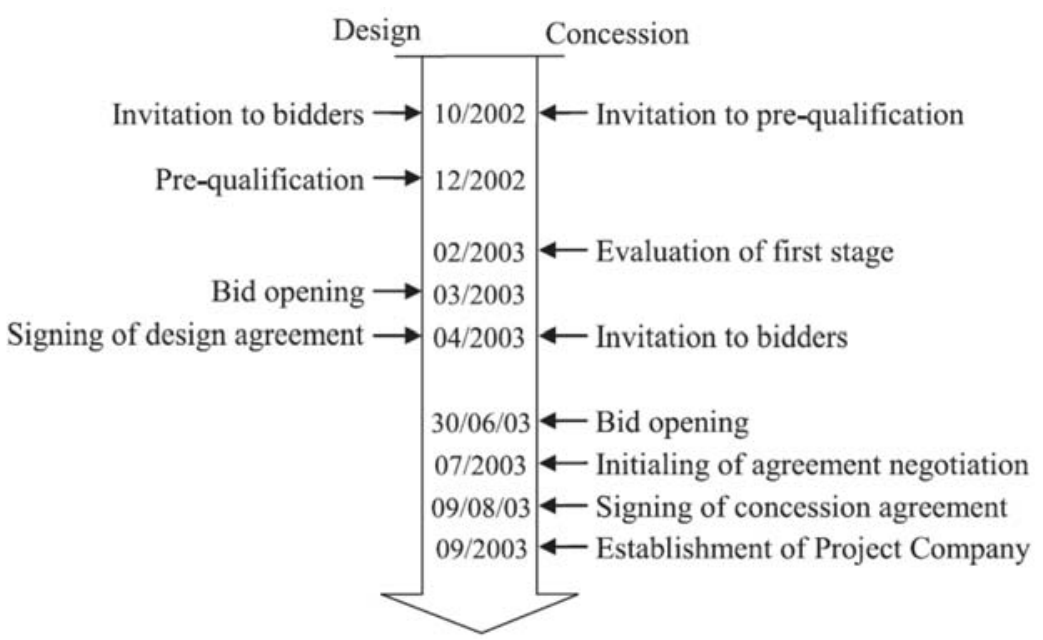

Figure 1: Development process of the Beijing National Stadium 
As shown in Figure 1, a two-stage competitive bidding was adopted for the procurement of concession. There were seven consortia applying for the pre-qualification in February 2003, of which five were qualified and entered the second round of bidding in April 2003 (National Stadium 2011a). Of these five, the top two successful bidders in the second round in the early July 2003 were Beijing Construction Engineering Group (BCEG) consortium and the CITIC consortium. A comprehensive evaluation method was adopted, which took into account optimized architectural design plan, construction plan, financing plan, operation plan, financial analysis, insurance plan, transfer plan and responses to contract document with a weighting of $10 \%, 15 \%, 20 \%, 25 \%, 5 \%, 5 \%, 5 \%$ and $15 \%$ (Zhou 2011).

The BCEG consortium was most likely to be awarded the concession, as it was ranked first. However, it dropped out in the late July 2003 as a result of failure to reach a common agreement with the BMG. The BMG then had to negotiate quickly with the CITIC Consortium (which was the second ranked bidder) from 2 August 2003 (Jing \& Wang 2008), and the two signed the concession agreement on 9 August 2003. It could be easily understood that the tight negotiation between the BMG and the CITIC Consortium would result in a rushed and imperfect agreement that left several unsolved issues for further negotiation and these led to many future problems (Liu et al 2010).

\subsection{Project partners and structure}

The major project structure of the Beijing National Stadium project is shown in Figure 2. On the same day when the concession agreement was signed, the CITIC Consortium also signed the National Stadium Agreement with the BMG and the Beijing Organizing Committee for the Games of the XXIX Olympiad (BOCOG) as well as the Joint Operation Contract with the Beijing State-Owned Assets Management Co., Ltd. (BSAM). The project company National Stadium Co., Ltd. (NSC) was set up later in September 2003, which was made up of the BSAM having a 58\% investment in the stadium and the CITIC Consortium with a $42 \%$ share of investment. It is worth noting that the BSAM was not to take a lead in the construction and management of the stadium and was also not to share any revenue within the concession period of 30 years (Zhou 2011). This meant that the BSAM was not responsible for the $58 \%$ of maintenance cost.

The CITIC Consortium was composed of three companies: the CITIC Group, the Beijing Urban Construction Group (BUCG) and the Golden State Holding Group (GSHG). The proportional equity of the three companies in the consortium was $65 \%, 30 \%$ and $5 \%$, respectively. The main area of expertise of the state-owned CITIC group lay in finance, industry and other service-related domains. The BUCG, also a state-owned group, had its hands in many areas of construction industry. GSHG, the only private partner, was established in the United States and invested in several water, sewage and waste management plants in China.

The Sino-Swiss Design Consortium, which included Swiss architecture firm Herzog de Meuron, ARUP Consulting Company, and China Architecture Design and Research Group, won the design bid through the international competitive bidding. Yet, the selection of other partners was not via bidding or negotiation. The main contractor was BUCG, one of the shareholders in the Consortium. The subcontractors were CITIC International Contracting Inc. and CITIC Guoan Group, subsidiary companies of the CITIC Group. China CITIC Bank was one of the loan lenders. 

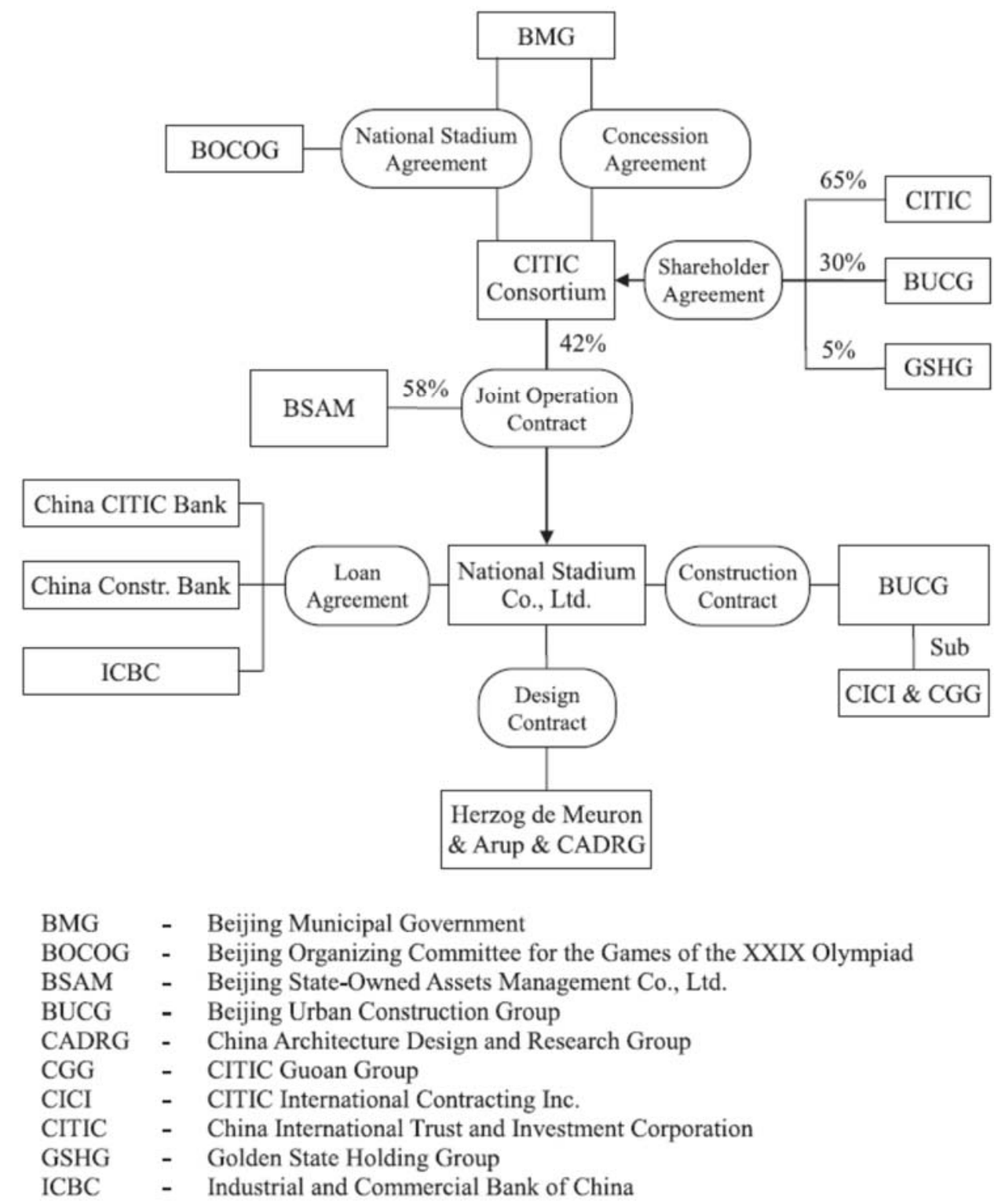

Figure 2: Project structure of the Beijing National Stadium

\subsection{Construction of the stadium}

In December 2003, the construction of the Beijing National Stadium broke ground in order to keep up the momentum of the preparations for the Olympics, even though architects were still working on preliminary design drawings (Ren 2008). As per the Concession Agreement, the construction of the stadium was to be completed by the end of 2006, but it actually got completed on 28 June 2008. The total construction cost was RMB 3.596 billion, which overran by 0.456 billion (National Audit Office 2009). Although in the end it got completed with good quality and safety measures - and played an important role in facilitating the success of the 2008 Beijing Olympics Games - the construction process of the stadium was not quite smooth.

In July 2004, 7 months after the stadium's ground breaking, the BMG ordered to stop the construction. The official reason cited by the BOCOG for this decision was that readjustments were needed in the architectural design and also to emphasize the idea of a cost-friendly Olympics (National Stadium 2007a). The key issue of the suspension was the safety and cost of the retractable roof. By the end of November 2004, the design work adjustments were complete. The plan to have a 
retractable roof was abandoned, thus reducing the percentage of steel originally needed by $22.3 \%$ and lowering the overall membrane structure by 13\% (National Stadium 2007b). The construction was thereafter resumed in December 2004.

However, one of the few specific requirements for the conceptual design of the stadium by the BMDPC was that the stadium "shall have a retractable roof, with the configuration designed to fully reflect the characteristics of modern sports buildings" (Ren 2008). The retractable roof became the focus for both architects in their design process and for bid evaluation committee members in their evaluation (ChinaVR 2003). The government later ordered the retractable roof to be removed to cut down the cost. This obviously wasted significant amounts of public and private sectors' time and money in the procurement stage, as the government should not have proposed the idea of a retractable roof in the bid invitation. The design change was criticized as evidence of the government's inconsistent decision-making process (Ren 2008).

\subsection{Operation of the stadium}

A sport facility project could be defined as a social infrastructure project in which the financial rewards are less and the operational demands are more complex than for economic PPP projects (Jefferies \& McGeorge 2009). It was more so for the National Stadium because of its extremely high construction cost and maintenance cost. Overall, the operation of the stadium was disappointing. On 20 August 2009, the BMG and the CITIC Consortium signed the Agreement on Further Strengthening the Operation, Maintenance and Management of the National Stadium to carry out a shareholding reform of the NSC. With this, the BSAM took the lead of operation management and the CITIC Consortium became a permanent stakeholder with a $42 \%$ shareholding (National Stadium 2009).

One of the reasons for the operation failure of the Beijing National Stadium was the significant change in business design and realization. Table 1 lists out the business design and its realization in the operation period. The planned revenue sources included sports events (i.e., lease for football games, lease for track and field competitions and lease for warm-up facilities), art and culture events, lease for corporate suites, advertisement, naming right, exhibition and tourism and souvenir shops. Among these, lease for corporate suites, art and culture events, and tourism and souvenir shops were supposed to be the principal income channels. It is worth noting that the revenue of lease for corporate suites and advertisement highly depends on the frequency of sports, art and culture events.

As shown in Table 1, the use of stadium for sports, art and culture events has been low. One of the reasons for this could be that the extremely high rent cost (about RMB 5-10 million) would scare away many possible event organizers (Liu 2010). Another reason is that the Beijing National Stadium is not only a sport stadium, but also a public symbol with high degree of political complexion. Therefore, to maintain its image in the public, the stadium could not hold low-grade or small events (Hu 2009; Liu 2010). Thereafter, there were also concerns about the market of corporate suites for long term lease because of the low frequency of sport, art, and culture events in the stadium. At the same time, the actual income of advertisement did not meet the expectation either. 
Table 1. Business design and realization of the National Stadium.

\begin{tabular}{|c|c|c|}
\hline No. & Planned revenue sources & Actual status \\
\hline 1 & Sports events & \\
\hline 1.1 & Lease for football games & $\begin{array}{l}\text { Beijing Guo'an Football Club refused to use the stadium as its arena. } \\
\text { Only two commercial football matches were held (one on } 8 \text { August } \\
2009 \text { and the other on } 8 \text { August 2010). }\end{array}$ \\
\hline 1.2 & $\begin{array}{l}\text { Lease for track and field } \\
\text { competitions }\end{array}$ & Tour De Ski China and The Race of Champions were held. \\
\hline 1.3 & Lease for warm-up facilities & $\begin{array}{l}\text { Twice in the winters Happy Snow Seasons were held. } \\
\text { The facilities were sometimes leased for youth baseball matches, } \\
\text { organizational activities, etc. }\end{array}$ \\
\hline 2 & Art and culture events & Four concerts and one opera have been held so far. \\
\hline 3 & Lease of corporate suites & $\begin{array}{l}\text { The lease started in June } 2010 \text {. But there would be a concern about its } \\
\text { market for long-term lease due to the low frequency of sport, art, } \\
\text { and culture events in the stadium. }\end{array}$ \\
\hline 4 & Advertisement & $\begin{array}{l}\text { The actual income did not meet the expectation because of the low } \\
\text { usage of the stadium. }\end{array}$ \\
\hline 5 & Naming right & $\begin{array}{l}\text { The NSC had to abandon the selling of naming right, as ordered by } \\
\text { the BMG. The key reason was that the Stadium has become a } \\
\text { political symbol to the public. }\end{array}$ \\
\hline 6 & Exhibition & $\begin{array}{l}\text { Some exhibitions on Beijing Urban Planning, Leading Chinese } \\
\text { Photographers, etc., were held. }\end{array}$ \\
\hline 7 & Tourism and souvenir shops & $\begin{array}{l}\text { Up to Jan } 2011 \text {, more than } 14.5 \text { million tourists had visited the } \\
\text { stadium. The income from souvenir shops was more than RMB } \\
8 \text { million. }\end{array}$ \\
\hline
\end{tabular}

According to the English website of National Stadium Co., Ltd. (2011b), there are three levels of corporate sponsorship: supporting business, corporate partner and title sponsor. It was reported that the first phase of partnership negotiations on the Beijing National Stadium had been completed by August 2008 with 13-14 enterprises selected and the cooperation revenue reached more than RMB 100 million (Du 2008). The second phase of partnership was also launched by the National Stadium Co., Ltd., to negotiate with up to seven domestic and overseas enterprises over title right (naming right) in August 2008 (Du 2008). However, it was later suspended by the BMG. Although stadium naming rights are an important source of income for big stadiums in countries with a strong sports industry, it would not happen in Beijing, where the Beijing National Stadium is a symbol of national aspirations (Huang 2009; Li 2009a). It is interesting to know that the name of Beijing National Stadium would not be commercialized but naming rights of other facilities within the stadium, such as the 84 executive boxes, may be considered for commercial branding (Ju 2011).

On the other hand, the revenue from tourism and souvenir shops has greatly beyond the expectation. It was reported that the income from the sale of tickets within 8 months after the Olympics reached RMB 260 million, which was about $70 \%$ of the total revenue (Li 2009b). But the ticket price has been accused as being too high ( $\mathrm{Li} 2008$ ), and the tourist revenue could not be sustained as the Olympic Games fever faded away (Li 2009b).

\subsection{Project performance analysis}

Given that the information is from the publicly available information in the news, websites, publications, etc., the objective of this section is not to obtain an accurate evaluation analysis but to discover the gain and loss of the government using PPP model from the view of public accountability.

In general, compared to a traditional project, the differences in the cash flow in a PPP project include a higher procurement cost, a later start of construction, a lower operation/maintain cost and a higher operation income, and it is like this because the private investors are supposed to bring in higher operation efficiency when investing in a PPP project (Yuan et al. 2010). This also how both the 
public and private partners could achieve a win-win result. In addition, the adoption of PPP model could reduce government investment at the start of the project and postpone the annual investment as well, which provide possibilities for the government to optimize the structure of budgetary expenditures (Cheung et al. 2010).

In the case of Beijing National Stadium, the BMG rushed the procurement process in order to commence the construction in late 2003. The construction did not start late, but with a cost of very tight contract negotiation. The stadium was planned to be completed by the end of 2006 but actually got completed on 28 June 2008. The total construction cost was RMB 3.596 billion, which overran by RMB 0.456 billion (National Audit Office 2009).

The purpose of improving operation efficiency was not accomplished at all as evident from the disappointing operation performance. It is highly possible that the project company could not make enough profits to cover the high investment. The contract change on 20 August 2009 made the private investors the permanent stakeholder and thereafter solved their problem. The private investors are now actually in the best economic position.

The purpose of optimizing the budgetary expenditure structure was partly achieved. After the contract change on 20 August 2009, the BSAM on behalf of the BMG was responsible for the 58\% of maintenance cost. In other words, the BMG invested 58\% of construction cost during the construction period from end 2003 to June 2008, and shared 58\% of maintenance cost from 1 year later. The adoption of PPP model in this project apparently did not greatly improve the budgetary expenditures of the BMG.

\section{Discussion}

Seemingly, PPP has become a more and more popular financing modality in China's infrastructure development. However, the legal framework for PPP implementation is not in place yet. In particular, PPP selection and design will vary depending on the specific conditions of the target project and the negotiation between government and private investors (Chen 2009). There is currently no guidance for value for money assessment or other mechanisms to ensure that PPP is the optimal financial option (Chan et al. 2010a). This may be ascribed to China's ongoing shift from a central to a market economy and the rapid pace of economic growth, where the growing demand for infrastructure to be developed may override concerns around the efficiency of its development and operation. Although a feasibility study and post-evaluation for a PPP project in China is typically conducted, information relevant to appraisal, project details and post-implementation is usually not publicized. There is no formal process for deciding on the type and extend of government support for PPPs (Wang et al. 2010). The government officers usually make decisions based on their own judgments or preferences, while the public society, including professionals and academicians, have little (or negligible) influence on the decision (Ke et al., 2012).

\subsection{Financial modality selection}

In this case, the most important question is whether a PPP was the most optimal financial option for the Beijing National Stadium. It is evident that the feasibility of adopting the PPP approach was not assessed before the BMG issued the invitation of bidding. The BMG rushed the procurement process in order to commence the construction in late 2003. Thereafter, the BMG negotiated very quickly with the CITIC Consortium on 2 August 2003 and signed the Concession Agreement on 9 August 2003 (Jing \& Wang 2008). 
In the absence of receiving value for money, the government should reconsider whether to continue with the PPP approach. As the principal driver for the private investors participating in a PPP project is to make profits, the only way to achieve a win-win result is improvement in construction and operation quality, reduction of construction and operation cost or improvement of efficiency (Yuan et al. 2010). However, the involvement of the CITIC Consortium did not bring in such an improvement. The CITIC Consortium also did not present an active attitude and innovative ability in creating revenue sources. In all conscience, the public image and government interference in selling naming rights and hosting small scale events was another cause of the disappointing operation performance.

The only benefit of adopting PPP in the National Stadium has been that the BMG could save quite a lot of investment at the special time, when it was about to construct many stadiums and improve the infrastructures for the coming 2008 Beijing Olympics. This may be the main driving force for the BMG to implement PPP.

In light of the discussion, PPP was obviously not the best option to procure Beijing National Stadium because of its high construction and maintenance cost, low revenue stream and great symbolic meaning.

\subsection{Government's decision-making}

Another significant problem in the case of Beijing National Stadium was the decision-making of the BMG, especially on the transparency and accountability of decision-making process and consequence. It is believed that the government officials now in China usually make decision based on their own judgments or preferences (Ke et al., 2012). Particularly in this project, the problematic and inconsistent decisions of the BMG included wrong identification of the retractable roof as one of the output specifications, suspension of selling name right and prohibition of holding small-scale or small events.

Retractable roof was one of the specific requirements for the conceptual design of the National Stadium (ChinaVR 2003) because the officials believed that "the stadium with a retractable roof will turn out to be a significant architectural legacy of the 2008 Olympics" (Ren 2008). The retractable roof became the focus in the 13 potential designs. Engineering firms were hired by architectural teams to design a safe and cost-effective roof. All of these efforts turned out to be an exercise in futility as the BMG later removed the retractable roof (Ren 2008). The driving force for the BMG to make such a huge change was a petition letter submitted to the Chinese prime minister from four senior members of the Chinese Academy of Sciences in July 2004. The petitioners criticized that the design of the National Stadium had potential problems in safety and stability. The BMG therefore suspended the construction and conducted a financial review. The suspension of construction and the following design change had greatly confused the public (Xinhuanet 2004a, 2004b). Why were the safety and stability problems not discovered during the long procurement period? Why did the BMG list the retractable roof as one of the output specifications?

\subsection{Difficulties for adopting PPP in social facilities}

Social infrastructure projects like sport facilities are characterized as generally being smaller in scale than economic infrastructure projects such as toll roads, power plants or water plants and, by their nature, also tend to be complex, particularly in terms of ongoing involvement with the community (Jefferies \& McGeorge 2009). The same situation is also seen in England's National Health Service, 
where the private financing of public capital investment is highly problematic and can have a serious impact on the finances and capacity of public authorities (Hellowell \& Pollock 2010).

Considerations for adopting PPP in a social infrastructure would therefore at least include the following: first, to proceed with the PPP model would mean that the project would be further delayed due to the long tendering and negotiation processes; second, with private sector involvement there would be a lack of government control over the project during the concession period; third, the business model would not be economically attractive enough for the private sector to be interested (Cheung \& Chan 2009).

However, it does not mean that PPP is always a bad choice to procure social infrastructure. Social PPPs can still significantly reduce construction time and reduce net present costs as long as contracting parties would pay much attention on non-value-added transaction costs, such as legal fees in the PPP bidding process (Jefferies \& McGeorge 2009), risks are properly identified and allocated to the parties best able to carry the risk (Cooper et al. 2005) and much transparency both in terms of the costs and decision-making would be in place. In other words, the experience and knowledge of contracting parties especially the government, as well as an advanced legal framework, are required for the successful implementation of PPP in social infrastructures.

\section{Conclusions}

PPP has been popularly used worldwide. Many local governments have regarded it as a panacea for infrastructure development. This paper has studied the much-speculated case of the Beijing National Stadium for 2008 Olympic Games in Beijing. The findings showed that there were several reasons that led to the case being procured back by the government. First, the BMG simply believed that the stadium with a retractable roof would be a significant architectural legacy of the 2008 Olympics, and identified it as one of the output specifications in the invitation of bidding, which was actually against the theme of Green Olympics for the Beijing Olympics. Second, the BMG adopted PPP in this project without a careful feasibility study, which was later proved as not the best procurement method. Lack of transparency in the government's decision-making also resulted in the public suspicion on the high entry price and service. Third, the strong government interference in the project like suspension of selling name right and prohibition of holding small-scale or small events caused a great change of income sources, which made it more difficult for project company to recover its investment. All these reasons clearly indicate that PPP model was not a better option for the Beijing National Stadium than the conventional procurement.

Therefore, PPP is not a panacea or fixed solution for infrastructure development, especially for social facilities, which are usually smaller in scale than economic infrastructure projects and also tend to be complex. It is more difficult to adopt PPP in social infrastructures than in economic infrastructures. The experience and knowledge of contracting parties, especially the government, as well as an advanced legal framework (e.g., how to choose a best procurement method and how to make decisions) are required for the successful implementation of PPP in social infrastructures.

The contribution of this paper is that the arrangement and performance of a large PPP sport project is analyzed and the problem areas scrutinized. The significance of this paper is that in future public clients who want to procure large-scale projects in developing countries like China via PPP model can go through the suggested considerations derived from this project to ensure that PPP is the best procurement option. 
One limitation of this paper is that the actual financial data during operation is not accessible due to its commercial-in-confidence nature. Structured interviews could not be conducted either given that this unsuccessful case study is not anonymous and individual interviewee could then be possibly identified. Therefore, this paper based its case study on the publicly available information of construction and operation performance in the news, websites, publications, etc. Another possible improvement of this paper is that much benefit may be derived from the comparison with a successful case.

\section{References}

Ashuri B, Kashani H, Molenaar K, Lee S, Lu J. 2012. Risk-neutral pricing approach for evaluating BOT Highway projects with government minimum revenue guarantee options. J Constr Eng Manage. 138(4):545-557.

Chan APC, Lam PTI, Chan DWM, Cheung E, Ke YJ. 2010a. Potential obstacles to successful implementation of public-private partnerships in Beijing and the Hong Kong Special Administrative Region. J Manage Eng. 26(1):30-40.

Chan APC, Lam PTI, Chan DWM, Cheung E, Ke YJ. 2010b. Critical success factors for PPPs in infrastructure developments: Chinese perspective. J Constr Eng Manage. 136(5):484-494.

Chen C. 2009. Can the pilot BOT project provide a template for future projects? A case study of the Chengdu No. 6 Water Plant B Project. Int J Proj Manage. 27(6):573-583.

Cheung E, Chan APC. 2009. Is BOT the best financing model to procure infrastructure projects? A case study of the Hong Kong-Zhuhai-Macau Bridge. J Prop Invest Finance. 27(3):290-302.

Cheung E, Chan APC, Kajewski S. 2010. The public sector's perspective on procuring public works projects - comparing the views of practitioners in Hong Kong and Australia. J Civil Eng Manage. 16(1):19-32.

China VR. 2003. Assessment and exhibition, competition for the architectural concept design for the National Stadium (the main stadium for the 2008 Olympic games). Available from: http://www.chinavr.net/bj2008/gjtiyuchang/index.htm (accessed 2011 March 14).

Cooper DF, Grey S, Raymond G, Walker P. 2005. Project risk management guidelines: managing risk in large projects and complex procurements. England: Wiley.

Curnow W, Jefferies MC, Chen SE. 2005. Unsustainable biddings costs: a critical issue for public private partnerships. In: Ng TS, editor. Public private partnerships: opportunities and challenges. Hong Kong: Centre for Infrastructure and Construction Industry Development, University of Hong Kong; p. 35-43.

Du XL. 2008. Companies in a flap for Bird's Nest naming rights. [cited 2008 Aug 20] Available from: http://www.chinadaily.com.cn/bizchina/2008-08/20/content_6955377.htm (accessed 2011 May 18).

Efficiency Unit 2008. An introductory guide to public private partnerships. 2nd ed. Hong Kong: Efficiency Unit.

Engel E, Fischer R, Galetovic A. 2010. The economics of infrastructure finance: public-private partnerships versus public provision. Eur Invest Bank Paper. 15(1):40-69.

European Commission. 2003. Guidelines for successful public-private partnerships: version 1.

Gibson H, Davies B. 2008. The impact of public private partnerships on education: A case study of Sewell Group Plc and Victoria Dock Primary School. Int J Edu Manage. 22(1):74-89.

Grimsey D, Lewis MK. 2004. Public private partnerships: the worldwide revolution in infrastructure provision and project finance. Cheltenham, UK: Edward Elgar.

Hellowell M, Pollock AM. 2010. Do PPPs in Social Infrastructure Enhance the Public interest? Evidence from England's National Health Service. Aus J Public Admin. 69(S1):23-34.

Hiller H. 2000. Mega-events, urban boosterism and growth strategies: an analysis of the objectives and legitimations of the Cape Town 2004 Olympic bid. Int J Urban Reg Res. 24(2):439-458. 
HM Treasury, UK. 2011. Public private partnerships. Available from: http://www.hmtreasury.gov.uk/ppp_index.htm (accessed 2011 March 31).

Hodge G, Greve C. 2005. The challenge of public-private partnerships-Learning from international experience. Cheltenham, UK:Edward Elgar.

Hu L. 2009. The strategy of being a sport center in Beijing is on it way [in Chinese]. Beijing Sports Industry Exhibition. [cited 2009 Aug 3] Available from: http://www.bjsports.org/showNews.jsp?id=66 (accessed 2011 May 10).

Huang DH. 2009. Name it right! - Selling stadium names to foreign brands a big risk. [cited 2009 Dec 11] Available from: http://www.beijingtoday.com.cn/business/name-it-right-sellingstadium-names-to-foreign-brands-a-big-risk (accessed 2011 May 18).

Jefferies M, McGeorge WD. 2009. Using public-private partnerships (PPPs) to procure social infrastructure in Australia. Eng Constr Archit Manage. 165):415-437.

Jing BJ, Wang LX. 2008. The Story behind CITIC participating in the national stadium project [in Chinese]. 21st Century Business Herald [cited 2008 Aug 8]. Available from: http://www1.21cbh. com/HTML/2008-8-8/HTML_E78CY0F0GHBL.html (accessed 2011 April 14).

Ju LC. 2011. Beijing's Bird's nest seeks well feathered occupants. [cited 2011 March 24] Available from: http://www.wantchinatimes.com/news-subclasscnt.aspx?id=20110324000031\&cid=1103 (accessed 2011 May 18).

Ke YJ, Wang SQ, Chan APC. 2012. Risk Management Practice in China's Public-Private Partnership Projects. J Civil Eng Manage. 18(5): 675-684.

Koppenjan JFM. 2005. The formation of public-private partnerships: lessons from nine transport infrastructure projects in the Netherlands. Public Admin. 83(1):135-157.

Lee $\mathrm{CH}, \mathrm{Yu}$ YH. 2011. Service delivery comparisons on household connections in Taiwan's sewer public-private-partnership (PPP) projects. Int J Proj Manage. 29(8):1033-1043.

Li B, Akintoye A, Edwards PJ, Hardcastle C. 2005. Perceptions of positive and negative factors drivers influencing the attractiveness of PPP/PFI procurement for construction projects in the U.K. Eng Constr Archit Manage. 12(2):125-148.

Li CL. 2009a. The second starting line [in Chinese]. [cited 2009 March 3] Available from: http://www.gemag.com.cn/gemag/index/news/?7574 (accessed 2011 May 18).

Li CL. 2009b. The operation predicament of the Bird's Nest [in Chinese]. [cited 2009 Sept 23] Available from: http://www.gemag.com.cn/gemag/index/news/?9859 (accessed 2011 May 18).

Li L. 2008. Public or private? National Sports Stadium accused of charging high ticket price [in Chinese]. Legal Daily [cited 2008 Nov 09]. Available from: http://www.legaldaily.com.cn/bm/content/2008-11/09/content_977374.htm (accessed 2011 May 18).

Liu TZ. 2010. Does the Bird's Nest really make a profit [in Chinese]? New Real Estate [cited 2010 March 12]. Available from: http://www.xindichan.com.cn/article_16335.html (accessed 2011 May 10).

Liu YW, Zhao GF, Wang SQ. 2010. Many hands, much politics, multiple risks - the case of the 2008 Beijing Olympics Stadium. Aus J Public Admin. 69(S1):85-98.

Meduri SS, Annamalai TR. 2013. Unit costs of public and PPP road projects: Evidence from India. J Constr Eng Manage. 139(1):35-43.

Malone N. 2005. The evolution of private financing of government infrastructure in Australia - 2005 and beyond. Aus Econ Rev. 38(4):420-430.

National Audit Office. 2009. Audit report on the financial statement of Beijing Olympic Games and construction of Olympic stadiums. Report No. 8; 2009 June 19. 
[National Stadium] National Stadium Co., Ltd. 2007a. BOCOG: 'Bird's Nest' construction suspension is to ensure cost-friendly Olympics. Available from: http:/www.ns.cn/en/generalinfo/eventschronicle/n214215077.html (accessed 2011 April 18).

[National Stadium] National Stadium Co., Ltd. 2007b. National Stadium news: retractable roof design canceled. Available from: http://www.n-

s.cn/en/generalinfo/eventschronicle/n214215078.html (accessed 2011 April 18).

[National Stadium] National Stadium Co., Ltd. 2009. Agreement on further strengthening the operation, maintenance and managementof the National Stadium signed. Available from: http://www.n-s.cn/en/dynamics/venueconstruction/n214611563.html (accessed 2011 April 19).

[National Stadium] National Stadium Co., Ltd. 2011a. Company introduction. Available from: http://www.n-s.cn/en/organizations/intro (accessed 2011 April 14).

[National Stadium] National Stadium Co., Ltd. 2011b. National Stadium sponsorship development. Available from: http://www.n-s.cn/en/business/sponsorship (accessed 2011 May 18).

Ren XF. 2008. Architecture and nation building in the age of globalization: construction of the National Stadium of Beijing for the 2008 Olympics. J Urban Affair. 30(2):175-190.

Sachs T, Tiong RLK, Wang SQ. 2007. Analysis of political risks and opportunities in public private partnerships (PPP) in China and selected Asian countries - survey results. Chin Manage Stud. 1(2):126-148.

Sharma S, Nayak S. 2013. Public-private community partnerships: An isodynamic model in water management. Int J Public Sector Manage. 26(2):135-145.

Tieva A, Junnonen JM. 2009. Proactive contracting in Finnish PPP projects. Int J Strateg Prop Manage. 13(3):219-228.

[UNIDO] United Nations Industrial Development Organization. 1996. Guidelines for infrastructure development through build-operate-transfer (BOT) projects. Vienna: UNIDO; p. 3-20.

Wang SQ, Ke YJ, Xie J. 2010. Public-private partnership implementation in China. In: ACCA Workshop - taking the stock of PPP and PFI around the world: country case study paper, 20 21 Sept 2010, Kyoto University.

Xinhuanet. 2004a. Bird Net's diet: what should we think of? [in Chinese] Available from: http://news.xinhuanet.com/comments/2004-08/08/content_1735519.htm (accessed 2014 Jan 17).

Xinhuanet. 2004b. Why was the Bird Net's petition letter so late? Available from: http://news.xinhuanet.com/comments/2004-08/13/content_1772160.htm (accessed 2014 Jan 17).

Xinhuanet. 2013. China widens market access in public services sectors. Available from: http://news.xinhuanet.com/english/china/2013-07/31/c_125097731.htm (accessed 2014 Jan 17).

Yin RK. 2002. Case study research: design and methods. 3rd ed. California, CA: Sage.

Yuan JF, Skibniewski MJ, Li QM, Shan J. 2010. The driving factors of China's public-private partnership projects in metropolitan transportation systems: Public sector's viewpoint. J Civil Eng Manage. 16(1):5-18.

Zhou J. 2011. Introduction of PPP financing model - the case of Beijing National Stadium [in Chinese]. Available from: http://wenku.baidu.com/view/ee3ca520dd36a32d73758181.html (accessed 2011 April 14). 